\title{
GLOBALIZAÇÃO, REGULAÇÃO \\ E NEONACIONALISMO: \\ UMA ANÁLISE DAS AGÊNCIAS REGULADORAS ${ }^{1}$
}

\author{
Antonio José Junqueira Botelho \\ Pontifícia Universidade Católica do Rio de Janeiro
}

\begin{abstract}
RESUMO
A liberalização da economia e a reforma do Estado dos anos 90 pareciam ter definitivamente relegado às paginas da história o nacionalismo industrial, marco da economia política brasileira no pós-guerra. Este, entretanto, experimenta um renascimento desde o limiar da década de 1990. Este trabalho busca entender a natureza do ressurgimento desse neonacionalismo tecnológico e industrial no bojo de agências reguladoras com elevado grau de autonomia cujas principais missões são a defesa da competição e do consumidor. Suas conclusões sugerem que as condições para seu ressurgimento estão ligadas à manutenção, nessas agências, de elites técnicas oriundas das instituições governamentais que lideravam o padrão desenvolvimentista, em conjunção com uma crescente regionalização de demandas, por sua vez decorrentes de pressões por um novo pacto federativo em uma conjuntura de crise.
\end{abstract}

PALAVRAS-CHAVE: reforma do Estado; agências regulatórias; neonacionalismo; desenvolvimentismo; fundos de fomento.

\section{INTRODUÇÃO}

Irritado com a ausência de qualquer estande de empresa brasileira na exposição Telecom-99 em Genebra - maior encontro de telecomunicações até então realizado no mundo -, o Ministro das Comunicações, Pimenta da Veiga, declarou: "Não podemos ter uma presença tão pálida como esta. Gostaria que na próxima vez não fosse assim. Temos que desenvolver alguma tecnologia brasileira para disputar posições mundiais". No mesmo dia, em Brasília, o plenário da Câmara dos Deputados aprovava, em votação simbólica (em virtude

\footnotetext{
1 Parte da pesquisa deste artigo foi efetuada quando o autor era Pesquisador Visitante da FAPERJ junto ao Instituto Gênesis para Inovação e Ação Empreendedora, da PUCRio; parte de sua redação ocorreu quando Pesquisador Visitante junto ao Programa de Pós-Graduação em Ciências Sociais da Universidade Estadual do Rio de Janeiro. Versões anteriores foram apresentadas no Seminário "As transversalidades contemporâneas: $\mathrm{C} \& \mathrm{~T}$, trabalho e cultura urbana", em 5 de julho de 1999, na UnB, assim como no workshop "Rio triple helix. Redes de inovação e relações Universidade-indústria-governo: perspectivas para o Brasil e América Latina", de 3 a 9 de junho de 1999, no Hotel Glória (Rio de Janeiro, RJ).
}

de acordo de lideranças), o Projeto de Lei criando o Fundo para o Desenvolvimento Tecnológico das Telecomunicações (FUNTTEL), voltado para promoção da pesquisa e do desenvolvimento na área. O FUNTTEL veio juntar-se ao Plano Nacional de Ciência e Tecnologia do Setor de Petróleo e Gás (CTPETRO) como mais uma política pública para inovação no país, formulada e implementada pelas agências reguladoras criadas nos últimos anos.

Desde o início da década de noventa, a crescente liberalização da economia e a reforma do Estado parecia ter definitivamente relegado às páginas da "história industrial" o nacionalismo que definiu a economia brasileira no pós-guerra. Se a década de oitenta foi nomeadamente a década perdida em termos de crescimento econômico na América Latina, a década de noventa é uma forte candidata à apelação de década perdida para a política industrial na América Latina em geral e no Brasil em particular. Analistas dos mais contrastantes matizes ideológicos e de horizontes disciplinares diversos parecem convergir para tal apreciação.

Assim, à esquerda, em um recente encontro no Rio de Janeiro de economistas da América Latina, o respeitado e perspicaz economista Antônio 
Barros de Castro clamava que a década atual repetiu largamente a anterior, chamada de década perdida. Barros de Castro, atacando a falência do neoliberalismo, conclamava então a necessidade de intervenção do Estado na economia, lembrando que em um grande número de países a volta ao protecionismo é de rigueur (A REABILITAÇÃO DO ESTADO, 1999, p. 14). Já à direita, Dionísio Dias Carneiro, um insuspeito economista neoliberal, ressalta que o crescimento real acumulado do investimento desde 1990 tem superado o do PIB, indicando uma superação da crise de investimento dos anos 80 e apontando o caminho para o crescimento. Este, segundo ele, ocorrerá graças à melhora na capacidade de transformar investimento em crescimento do PIB, proporcionada, entre outros motivos, pelo abandono dos programas setoriais sustentados por lobbies, e pelos impactos esperados da "reforma do Estado, que começou com a privatização do aparelho estatal, avança com a implantação de agências reguladoras, norteando e fiscalizando a competição em setores-chave como petróleo, telecomunicações e produção e distribuição de energia" (CARNEIRO, 1999)2 ${ }^{2}$. Mal podia ele imaginar que os impactos dessas agências em alguns setores serão mais diretos do que aqueles previstos pela teoria.

Pois qual lebre escondida na cartola, todavia, uma política industrial de cunho tecnológico ressurge no Brasil, na contramão tanto do pessimismo niilista ou do otimismo cego daqueles analistas que não viam qualquer possibilidade de seu ressurgimento no ambiente hegemônico da ideologia neoliberal que se instalou no país desde o início da década passada.

Paradoxalmente, foi no limiar dessa década que esse nacionalismo renasceu no bojo de instituições epítomes da modernização burocrática do país, as agências reguladoras - e revigorado pela regionalização político-econômica induzida pela globalização e pela crise fiscal do Estado. O presente trabalho busca entender a natureza do ressurgimento desse neonacionalismo tecnológico e industrial nessas agências reguladoras de atividades econômicas estratégicas nos setores de telecomunicações, de petróleo e de energia elétrica.

Essas agências, que possuem um elevado grau

2 Para uma visão semelhante que privilegia a defesa do consumidor como uma nova tarefa nobre realizada pelas agências reguladoras, ver Franco (1999). de autonomia e têm como missões principais, em princípio, a defesa da competição e do consumidor, foram criadas a partir da liberalização e privatização nas áreas de telecomunicações, energia elétrica e petróleo. Novas agências vêm sendo criadas também para regulação social e de serviços (vigilância sanitária, águas, aviação civil, transportes etc.).

As conclusões deste trabalho sugerem que as condições para a emergência desse neonacionalismo decorrem da manutenção nessas agências de elites técnicas oriundas das instituições governamentais que lideravam o desenvolvimentismo anterior, aliadas e/ou em conjunção com uma crescente regionalização de demandas por emprego e desenvolvimento, conseqüência, por sua vez, em parte das pressões por um novo pacto federativo numa conjuntura de crise. Assim, em caráter preliminar, sugerimos que as agências com um corpo técnico mais bem formado são justamente aquelas que avançaram mais rapidamente na definição e implementação de programas de apoio setorial de maior escopo e intensidade. Um outro fator que também revela-se importante para a trajetória divergente de tais programas nos três setores em questão é a permanência na cadeia de produção ou de provisão de serviços em cada setor analisado de instituições corporativas estatais fortes.

\section{MARCO ANALÍTICO E METODOLOGIA}

Ao longo da última década, o Estado brasileiro, pressionado pela exaustão do modelo de substituição de importações, pelo impacto da globalização e pela dupla crise - fiscal e de governabilidade -, tem buscado reinventar-se através da liberalização econômica, da transformação estrutural e da reforma administrativa (TEIXEIRA \& SANTANA, 1994; JOHNSON, 1996; LATTMANWELTMAN, 1996). Um importante componente desse processo foi a reforma regulatória, que compreendeu, com diferentes graus de variação segundo cada setor: 1) a quebra de monopólio estatal; 2) a privatização de empresas estatais; 3 ) a formulação de um novo marco regulatório; 4) o estabelecimento de conselhos industriais setoriais, e 5) o estabelecimento de agências reguladoras financeiramente autônomas e, em princípio, politicamente independentes.

Esses múltiplos desenvolvimentos terão um impacto crítico nas futuras estrutura e orientação da política industrial, principalmente aquelas focalizadas na promoção da inovação, e a médio prazo nas próprias estrutura e práticas de outras políticas 
públicas setoriais, por oferecerem respostas a uma série de dilemas (anomalias paradigmáticas) acumulados na política industrial e de inovação brasileira, ainda sem solução viável ou consolidada. Também apresentam uma oportunidade única para a implementação de orientações de pesquisa e produção da inovação voltadas para o desenho de um novo marco institucional das relações entre Universidade-indústria e governo (GRINDLE,1996). O presente trabalho examina principalmente os esforços tecnológicos potenciais dos marcos regulatórios e atuais das agências, e busca analisar de maneira preliminar as divergências nesses esforços, suas causas e conseqüências.

Por um lado, a privatização nos setores em questão desmantelou importantes centros de pesquisa e desenvolvimento, desestruturando importantes linhas de pesquisa e programas de financiamento à pesquisa, em um contexto de penúria financeira generalizada para a área de inovação como um todo, salvo raras exceções em sub-áreas consideradas estratégicas pelo governo ${ }^{3}$. Por outro lado, a criação de agências reguladoras setoriais, para telecomunicações (ANATEL), energia elétrica (ANEEL) e petróleo e gás (ANP) criou oportunidades para o estabelecimento de um novo marco institucional para a pesquisa setorial. As forças políticas e a configuração institucional de política pública que moldam essas reformas setoriais, particularmente naqueles aspectos que tocam no papel das agências reguladoras na promoção de mecanismos e recursos humanos para a inovação, são o objeto do presente artigo. A metodologia empregada baseou-se na coleta e análise de documentos primários e secundários e em entrevistas abertas tanto com atores setoriais quanto com aqueles ligados à reforma regulatória.

O resultado das reformas em cada área apresenta importantes diferenças. Nas conclusões, a variabilidade é explicada de maneira preliminar pela força e capacidade de mobilização dos atores com interesses na ciência e na tecnologia em cada setor, pelas oportunidades e barreiras apresentadas pelos diferentes contextos institucionais e setoriais, e pelo grau de competição de interesses existente ou potencial entre os atores relevantes para a re-

\footnotetext{
3 Por exemplo, o setor espacial, cujo financiamento para o desenvolvimento da inovação tem sido mantido, ainda que a duras penas e com reduzidos valores (Política do espaço, 1999).
}

forma nas estruturas e orientação da pesquisa e desenvolvimento nas agências (VOGEL, 1996).

Este trabalho busca contribuir de maneira mais geral para o esforço de compreensão e de construção de um marco analítico adequado sobre as vinculações entre mudanças nas estruturas de governança ou instituições e as mudanças nas políticas públicas (REMMER, 1997; MAJONE, 1999 , p. 5). Contribui também para o debate acerca do papel do Estado no desenvolvimento econômico nesta era neoliberal, quando o Estado tende a desaparecer dos marcos analíticos (EVANS, 1997). Finalmente, contribui para o entendimento sistemático das conseqüências políticas, jurídicas e institucionais de mudanças na estrutura de governança (MAJONE, 1999, p. 6).

\section{POLÍTICA DE INOVAÇÃO E REGULAÇÃO}

À medida que a inovação torna-se a peça central da política governamental para competitividade, tendo em vista seu caráter neutro no contexto de crescentes conflitos comerciais, as interações entre os diferentes agentes envolvidos na produção da inovação, seja no formato de redes de clusters, seja em outros, adquirem uma importância renovada. O conhecimento e compreensão dessas novas formas e a especificação de formas imaginadas prescritas por novas teorias de crescimento econômico endógeno e de mudança econômica evolutiva, constitui-se o insumo crítico para a formulação de uma nova geração de políticas de apoio a pesquisa e à inovação, em lugar da tradicional política científica e tecnológica (BRANSCOMB \& KELLER, 1998b). Esse insumo é crítico também do ponto de vista das relações econômicas internacionais do país, na medida em que subsídios à inovação ainda são aceitos pelos tratados de comércio internacional vigentes.

A partir das reformas regulatórias ocorridas nos países industrializados na última década e face às demandas por competitividade baseada na competência tecnológica nasceu um interesse pela compreensão das relações entre regulação e inovação. Segundo a OECD elas são diversas e complexas, devido a: 1) existirem vários tipos de regulação (econômica, social e administrativa); 2) haver impactos da regulação sobre a inovação, e 3) haver efeitos também da tecnologia sobre a regulação $(\mathrm{OECD}, 1996)^{4}$.

4 Um balanço inicial da reforma regulatória na América Latina está em Manzetti (2000b). 
QUADRO 1 - Regulação e inovação

Tipos de regulação

- Econômica - busca melhorar a eficiência do mercado na produção de bens e serviços

- Social - protege o meio ambiente e a segurança e a saúde da sociedade como um todo

- Administrativa - gera o funcionamento dos setores público e privado, fixando condições básicas para o desenvolvimento tecnológico

Agenda da interface regulação-inovação

- Compreensão dos laços entre regulação e tecnologia - o processo regulatório deve monitorar permanentemente os impactos da mudança tecnológica

- Introduzir competição - em qualquer setor econômico um certo grau de competição entre firmas é essencial para a inovação

- Reduzir a regulação - na busca de eficiência econômica e inovação, a reforma regulatória deve eliminar regulamentos duplicadores, onerosos e ineficientes, principalmente para auxiliar pequenas e médias empresas (PMEs)

- Usar marcos geradores de tecnologia - o maior uso possível deve ser feito de marcos regulatórios ou alternativas promotoras de tecnologia, tais como instrumentos econômicos, acordos voluntários e normas de desempenho, ao invés de desenho

- Harmonização internacional - os países devem buscar maior compatibilidade entre suas regulações, assim como eliminar incertezas, ineficiências e barreiras de mercado que diminuam a inovação

Fonte: OECD (1996).

O objeto de análise aqui é a "reforma regulatória" entendida como regulação econômica, na medida em que compreende desregulamentação, privatização e abertura de mercados à competição; mudanças com um impacto certo no processo de inovação, particularmente na firma, ainda que se referindo também, em parte, à reforma como regulação administrativa (pois o enxugamento e a melhoria da eficiência dos regulamentos contribui para que as firmas centrem seus esforços na inovação). Ademais, agências regulatórias, em nome de assegurar regras básicas e razoáveis para os agentes econômicos, são capazes de pressionar em favor de mudanças estruturais no ambiente no qual a inovação ocorre; por exemplo, em direitos de propriedade intelectual. Como a OECD expôs sucintamente, os efeitos da regulação na inovação são múltiplos e complexos: "[...] regulações podem [...] erigir barreiras ao desenvolvimento de novos e melhores produtos, e novos processos. Elas podem encorajar ou desencorajar os esforços de pesquisa de firmas. Elas podem distorcer a escolha de tecnologias que são exploradas ou adotadas. Elas podem criar barreiras à inovação ao aumentar os custos de incerteza no processo de desenvolvimento. E podem afetar a difusão de tecnologia [...]. A reforma regulatória, logo, está dirigida para as deficiências na regulação que afetam negativamente o processo de inovação da pesquisa à difusão, ao mesmo tempo que alcança os benefícios da regulação" (OECD, 1996, p. 12) .

\footnotetext{
5 Por exemplo, nos países da OCDE a taxa de difusão para telefones celulares está diretamente relacionada aos regimes
}

\section{ANTECEDENTES 6}

O programa brasileiro de privatizações até recentemente carreou cerca de $\mathrm{R} \$ 84,6$ milhões para os cofres do Estado, obtidos com a venda de 107 empresas. Por exemplo, somente a reforma completa do setor de telecomunicações, incluindo receitas da privatização e taxas de concessão, deverá levar R $\$ 32$ bilhões para o Tesouro ${ }^{7}$. A reforma regulatória, amplamente definida para incluir a liberalização econômica e a privatização, constitui sem sombra de dúvida o item mais importante da reforma do Estado no Brasil. Suas origens remontam ao início dos anos noventa do abortado governo Collor (1990-1992) ${ }^{8}$. Sua implementação ganhou velocidade, entretanto,

regulatórios nacionais, e o uso de internet é maior em mercados competitivos de infraestrutura de telecomunicações em contraposição àqueles restritos (OECD, 1996, p. 12).

6 Esta seção baseia-se em pesquisa própria do autor, assim como em Almeida e Moya (1997), Nunes (1998) e Almeida (1998a; 1998b).

7 Uma discussão recente da privatização na América Latina está em Manzetti (2000a).

8 Embora uma comissão de desestatização houvesse sido criada já em 1981, seguida de arranjos similares nos anos seguintes. No governo Collor foram lançadas as privatizações (parciais e totais) dos setores de aço, petroquímica e fertilizantes, e continuadas relutantemente no governo intermediário de Itamar Franco (1992-1994). O Programa Nacional de Desestatização (PND), estabelecido em 1990, definiu uma lista inicial de firmas estatais a serem privatizadas, concedeu ao Executivo o poder de modificá-la e nomeou o BNDES como gestor do programa. 
durante o primeiro governo Cardoso (1994-1998). Em 1995-1996 votou-se uma lei no Congresso Nacional permitindo a inclusão dos monopólios de Estado, até então protegidos pela Constituição, na lista do programa: telecomunicações, eletricidade, transporte marítimo, e petróleo e gás. A reforma negociada pelo Executivo (ALMEIDA, 1998b) que se seguiu acelerou o ritmo da reforma regulatória, de maneira que entre 1995 e 1998 , trinta empresas foram privatizadas, frente a um total de 56 no período 1990-1998.

O processo de reforma ocorreu com uma baixa oposição dos grupos sociais atingidos e das instâncias políticas relevantes. Da mesma forma, não houve virtualmente nenhum debate público em torno da questão no seio da comunidade científica do país sobre o futuro dos programas de pesquisa em geral nas áreas objeto da reforma, e em particular acerca do destino dos centros de pesquisa existentes nos setores cobertos aqui estudados. $\mathrm{E}$, a despeito das elevadas esperanças de analistas de primeira hora - de que a manutenção desses centros seria um tema maior na agenda da política pública para a privatização -, de maneira geral elas não se concretizaram (ao menos nos setores aqui cobertos em seus estágios iniciais de implementação).

\section{POLÍTICA DE INOVAÇÃO: A REFORMA REGULATÓRIA NO BRASIL}

É razoável afirmar que até recentemente a maioria da pesquisa tecnológica no país era realizada em laboratórios públicos de pesquisa, com uma concentração nas três áreas objeto desse estudo: energia elétrica, Centro de Pesquisas Elétricas (CEPEL); telecomunicações, Centro de Pesquisa e Desenvolvimento ( $\mathrm{CPqD}$ ), e petróleo e gás, Centro de Pesquisas da Petrobrás (CENPES). Conjuntamente, esses três laboratórios tiveram em média, ao longo dos últimos anos, um orçamento da ordem de US\$500 milhões. Esse valor representa cerca de $10 \%$ das despesas nacionais em C\&T (US\$5,9 bilhões em 1995, incluindo despesas com as Universidades públicas) ou ainda cerca de $30 \%$ das despesas das firmas em inovação tecnológica (US $\$ 1,8$ bilhões em 1995, incluindo investimentos operacionais e em capital em pesquisa e desenvolvimento e engenharia) (LANDI, 1998).

\section{V.1 Telecomunicações}

A Agência Nacional de Telecomunicações (ANATEL) foi criada em agosto de 1997, e, dife- rentemente de outras agências criadas na época, houve a obrigação de ter seu quadro de pessoal aprovado pelo Congresso Nacional. Sua criação, bem como a privatização do setor, iniciado já em 1996 com a concessão da banda B da telefonia celular, transcorreu sem grandes obstáculos, devido à grande força política e capacidade de negociação do ministro da área, Sérgio Motta, falecido prematuramente em abril de 1998.

Dentre os objetivos da lei de reforma do setor, de dezembro de 1996, considerados críticos para a consolidação de dois princípios essenciais - a introdução da competição na exploração dos serviços e a universalização do acesso aos serviços básicos -, está o que determina que em um ambiente competitivo deve-se criar oportunidades atraentes de investimento e de desenvolvimento tecnológico e industrial. Nesse objetivo consolidam-se três intenções básicas. A primeira delas associa-se à necessidade de atração de capitais privados, por meio da criação de oportunidades para investimento no setor. A segunda diz respeito à construção de um ambiente que propicie o desenvolvimento da competição justa no mercado e facilite a consolidação de novos participantes. Finalmente, a terceira refere-se à geração de condições que estimulem a pesquisa e o desenvolvimento tecnológico e industrial. Esses objetivos de cunho tecnológico foram consolidados na Lei Geral das Telecomunicações Brasileiras (LGTB) de julho de 1997, como mostrado no Quadro 2 abaixo.

A ANATEL está instalada em Brasília e seu quadro de pessoal é composto principalmente por funcionários transferidos do Ministério das Comunicações, já que nos seus primeiros 24 meses de funcionamento pôde requisitar funcionários de qualquer organização governamental. Sua estrutura compõe-se de um presidente e cinco diretores executivos com mandatos de cinco anos, sem direito a recondução. Os recursos iniciais da agência foram da ordem de $\mathrm{R} \$ 10$ bilhões provenientes de concessões e outorgas (banda B, radiodifusão, transmissão de sinais por satélite e TV a cabo), além de $\mathrm{R} \$ 250$ milhões anuais oriundos da taxa do Fundo de Fiscalização das Telecomunicações (FISTEL) ${ }^{9}$.

\footnotetext{
9 O FISTEL é um "fundo de natureza contábil [...] destinado a prover recursos para cobrir despesas feitas pelo Governo Federal na execução da fiscalização de serviços de telecomunicações, desenvolver os meios e aperfeiçoar a técnica necessária a essa execução" (ANATEL, 1996).
} 


\section{QUADRO 2 - Desenvolvimento tecnológico na LGTB}

ART. 76 - INCENTIVOS - As empresas prestadoras de serviços e os fabricantes de produtos de telecomunicações que investirem em projetos de pesquisa e desenvolvimento no Brasil, na área de telecomunicações, obterão incentivos nas condições fixadas em lei.

ART. 77 - FUNDO PARA O DESENVOLVIMENTO TECNOLÓGICO DAS TELECOMUNICAÇÕES - O Poder Executivo encaminhará ao Congresso Nacional, no prazo de cento e vinte dias da publicação da Lei, mensagem de criação de um fundo para o desenvolvimento tecnológico das telecomunicações brasileiras, com o objetivo de estimular a pesquisa e o desenvolvimento de novas tecnologias, incentivar a capacitação dos recursos humanos, fomentar a geração de empregos e promover o acesso de pequenas e médias empresas a recursos de capital, de modo a ampliar a competição na indústria de telecomunicações.

ART. 78 - POLÍTICA CREDITÍCIA, FISCAL E ADUANEIRA - A fabricação e o desenvolvimento no país de produtos de telecomunicações serão estimulados mediante adoção de instrumentos de política creditícia, fiscal e aduaneira.

ART. 190 - PESQUISA E DESENVOLVIMENTO DA TELEBRÁS - Na reestruturação e desestatização da Telecomunicações Brasileiras S.A. - TELEBRÁS deverão ser previstos mecanismos que assegurem a preservação da capacidade em pesquisa e desenvolvimento tecnológico existente na empresa.

Parágrafo Único: Para o cumprimento do disposto no caput, fica o Poder Executivo autorizado a criar entidade, que incorporará o Centro de Pesquisa e Desenvolvimento da TELEBRÁS, sob uma das seguintes formas: I empresa estatal de economia mista ou não, inclusive por meio da cisão a que se refere o inciso I do artigo anterior; II - fundação governamental, pública ou privada.

Fonte: $\mathrm{CPqD}(\mathrm{s} / \mathrm{d})$.

Dois outros fundos estabelecidos pela lei de criação da ANATEL, cujas prioridades, entretanto, são definidas pelo Ministério das Comunicações em consulta com outros ministérios, e que foram apenas recentemente regulamentados, são o Fundo de Universalização (FUST) ${ }^{10}$ e o Fundo de Desenvolvimento Tecnológico das Telecomunicações (FDDT, mais recentemente FUNTTEL) ${ }^{11}$.

10 A Exposição de Motivos n. 12/96 fala da criação de um fundo específico. Nesse caso, todas as operadoras participariam do financiamento das obrigações de serviço universal, através de uma contribuição proporcional a suas respectivas receitas. O órgão regulador seria o responsável por administrar esse fundo, definir o valor das contribuições e escolher, de maneira adequada, a empresa a incumbir-se da prestação do serviço universal em cada situação específica. Por ser politicamente mais simples, essa opção é a que parece ser a mais recomendável. O FUST foi, finalmente, instituído em 17 de agosto de 2001. Sobre a regulamentação do FUST, cf. Anatel (2000).

11 Já na Exposição de Motivos de dezembro de 1996 mencionava-se que: "Para estimular a indústria e a tecnologia nacionais, em linha com as razões apontadas no item $7 \mathrm{da}$ parte II desta Exposição de Motivos, o Projeto propõe, no Art. 71, que as empresas prestadoras de serviços de telecomunicação que investirem em projetos de pesquisa e desenvolvimento no Brasil, na área de telecomunicações, obterão incentivos, nas condições fixadas em lei. Tais incentivos deverão ser, portanto, objeto de diploma legal que trate especificamente da matéria”. Adicionalmente, o Art. 72 do projeto estabelece que poderão ser estimulados o desenvolvimento e a fabricação, no país, de produtos de telecomunicações, mediante adoção de instrumentos de política fiscal e aduaneira. O fundo foi estabelecido pela lei estabelecido pela Lei n. 10 052, de 28 de novembro de 2000. Para maiores informações, consultar: Ministério das Comunicações (2000a).
A implementação desses fundos esteve pendente até o final de 2000, e tem havido dúvidas quanto à viabilidade dos mesmos ante os ataques do Tesouro Nacional no orçamento da ANATEL. A instituição do FUNTTEL ocorreu finalmente no final de 2000, e sua regulamentação em janeiro de 2001. As empresas prestadoras de serviços de telecomunicações deverão contribuir com $0,5 \%$ sobre a receita bruta, a partir de $1^{\circ}$ de abril de $2001^{12}$. Segundo o Secretário-Executivo do Ministério das Comunicações, Juarez Quadros, em 2001, o patrimônio do FUNTTEL seria de R \$220 milhões, contando inicialmente com $\mathrm{R} \$ 100$ milhões transferidos do FISTEL. Para 2002, a expectativa de arrecadação é de R $\$ 125$ milhões; para 2003, de R\$131 milhões; para 2004, de R \$138 milhões, e para 2005, de R\$140 milhões (MINISTÉRIO DAS COMUNICAÇÕES, 2000b).

Também houve dúvidas por parte das comunidades científica e tecnológica quanto ao apoio à

\footnotetext{
12 Também ajudarão a formar o caixa do FUNTTEL uma parcela de, no mínimo, $1 \%$ das receitas apuradas pela ANATEL nas concessões de serviços de telecomunicações no regime público, na expedição de autorizações para exploração de serviços no regime privado e nas outorgas de radiofreqüências. O FUNTTEL também receberá uma parcela de, no mínimo, $1 \%$ dos recursos provenientes das taxas de fiscalização de instalação de estações e das receitas apuradas com a aprovação de laudos de ensaio pela agência reguladora. Diz a lei que o FUNTTEL também contará com um patrimônio inicial de $\mathrm{R} \$ 100$ milhões, recursos que serão transferidos do FISTEL (Fundo de Fiscalização das Telecomunicações).
} 
tecnologia nacional nas atitudes da ANATEL. Essas ressalvas foram parcialmente atendidas em cumprimento ao Artigo 78 da LGTB, quando o governo, através do Diretor-Geral da ANATEL, Renato Guerreiro, adotou medidas para impedir que empresas estrangeiras vencedoras dos leilões de privatização do Sistema Telebrás discriminassem fornecedores nacionais, favorecendo parceiros no exterior. Os estrangeiros também terão restrições para fazer contratos de assistência técnica com suas matrizes. A indústria nacional de equipamentos de telecomunicações terá preferência nos contratos das empresas que vencerem as licitações. A operadora deverá contratar o fornecedor nacional sempre que este conceder preço, prazo e qualidade técnica semelhantes aos dos estrangeiros. Se houver empate entre dois fornecedores nacionais, a prioridade seria dada à empresa que usar tecnologia desenvolvida no Brasil (O Estado de São Paulo, 20.maio.1998).

Desde a sua criação, a atualmente extinta Telebrás contava em sua estrutura com um Departamento de Pesquisa e Desenvolvimento, que evoluiu em 1976 para uma Diretoria de Tecnologia, à qual se subordinou o Centro de Pesquisa e Desenvolvimento (CPqD), instalado na cidade de Campinas, em São Paulo. Na década de 70, quando a política governamental baseou-se na substituição de importações, o poder de compra da Telebrás foi utilizado como o principal instrumento de consolidação de um parque industrial no Brasil para a fabricação de equipamentos, materiais e sistemas de telecomunicações, em parte com a utilização de tecnologia desenvolvida localmente.

Essa política frutificou na década de 80 , com a consolidação do $\mathrm{CPqD}$ através da ativação comercial de produtos lá desenvolvidos, como as centrais de comutação digital da família "Trópico", as fibras ópticas, o telefone padrão, as antenas de comunicações por satélite e os multiplexadores digitais para telefonia e para telegrafia. No final daquela década, mais de $95 \%$ dos investimentos da Telebrás eram canalizados para gastos internos no Brasil, com as importações restritas apenas a alguns componentes especiais e a instrumentos de teste e medição. A exposição do setor industrial brasileiro à competição internacional, e os limites impostos pela legislação à utilização do poder de compra do Estado, diretamente ou através de suas empresas controladas, acabaram resultando em um aumento substancial do volume anual de importações do setor, que passaram dos $5 \%$ sobre os investimentos totais, observados no final dos anos 80, para cerca de 20\% em 1996 (MINISTÉRIO DAS COMUNICAÇÕES. GABINETE DO MINISTRO, 1996).

No marco da reestruração das telecomunicações brasileiras, como previsto na LGTB e com a extinção da Telebrás ao término da venda de seus ativos, o CPqD foi transformado em maio de 1998 em fundação privada sem fins lucrativos, dirigida por um conselho curador e com um DiretorExecutivo, sob a fiscalização do Ministério Público. Seu financiamento, que era da ordem de $\mathrm{R} \$ 100$ milhões em 1997 (pagos pelas operadoras componentes do Sistema Telebrás em regime de condomínio), ficou garantido pelos regulamentos da privatização, pois as empresas privatizadas têm por obrigação apoiá-lo por três anos com $\mathrm{R} \$ 124$ milhões anuais, garantidos através da assinatura em maio de 1998 de contratos entre o $\mathrm{CPqD}$ e as operadoras de telefonia fixa e celular, bem como pela Embratel, para usos dos laboratórios do centro e de 15 softwares já em utilização pelas operadoras (Jornal do Brasil, 04.jun.1998). Todavia, a expectativa de que esses recursos fossem repassados ao $\mathrm{CPqD}$ em julho não se haviam ainda materializado até agosto de 1998, quando o Presidente da Comissão de C\&T da Câmara dos Deputados dizia ir buscar os novos donos das operadoras para realizar os investimentos estipulados nos contratos de concessão (Jornal do Brasil, 07.ago.1998).

O CPqD propôs ao Congresso que se incluísse na regulamentação do Fundo para o Desenvolvimento Tecnológico das Telecomunicações (originalmente FDTT, hoje FUNTTEL) a modalidade de "recursos não reembolsáveis" para o financiamento de projetos de $\mathrm{P} \& \mathrm{D}$ de médio e largo prazo de interesse do país, a serem conduzidos pelo CPqD em colaboração com Universidades. Propôs também vincular o financiamento do FUNTTEL a recursos estáveis, como um percentual do faturamento das empresas prestadoras de serviços de telecomunicações, ao invés das dotações orçamentárias, rendimentos de aplicações do fundo e doações, como previsto no projeto original enviado pelo governo brasileira ao Congresso Nacional em novembro de 1997. Finalmente, sugeriu que se destinasse a si próprio uma parcela desses "recursos não reembolsáveis" do FDTT nos termos do Artigo 190 da LGTB (GRACIOSA, 1998).

Tão-somente em meados de outubro de 1999 
o plenário do Congresso Nacional aprovou o Projeto de Lei criando o FUNTTEL, estipulando que todas as empresas prestadoras de serviços de telecomunicações contribuam com $0,5 \%$ de suas receitas brutas, e as instituições autorizadas a promover serviços por meio de ligações telefônicas com $1 \%$ sobre a arrecadação bruta. $\mathrm{O} \mathrm{CPqD}$ saiu vitorioso até então, já que o projeto garante a aplicação de 20\% dos recursos do FUNTTEL para o CPqD entre agosto de 2001 e agosto de 2002, período imediatamente posterior à vigência dos atuais contratos entre o instituto de pesquisa e as operadoras (ATAQUE AO REAJUSTE, 1999). Uma das principais modificações feitas no projeto original do Executivo foi a criação de um Conselho Gestor dos recursos, ao invés de destiná-los ao BNDES. Tal conselho, no molde do Conselho Gestor do CTPETRO (vide abaixo), é composto por representantes dos ministérios, além da ANATEL, da Finep e do BNDES.

Todavia, o poder de controle da transferência de tecnologia passa no momento - ao menos em termos de produção - pela política econômica orientadora de todas as outras políticas de desenvolvimento do país. Essa política pauta-se pelo controle da inflação e, conseqüentemente, pela interpretação de seus guardiões: defesa do real e da balança comercial brasileira, principalmente em vista da crescente fuga de capitais provocada pela crise da desvalorização do real. A explosão do mercado brasileiro de telecomunicações, principalmente em conseqüência da expansão em larga escala da telefonia celular, gerou um sério desequilíbrio comercial no setor. A importação total de produtos acabados (transceptores, telefonia, periféricos e computadores) passou de US $\$ 247$ milhões em 1990 para US\$725 milhões em 1993. Com o crescimento rápido da telefonia celular, os resultados dispararam em 1996 e atingiram a marca de US $\$ 1,8$ bilhão, sendo que os transceptores representaram US\$618 milhões e a telefonia US\$315 milhões. Em 1998 a trajetória de crescimento continuado levou o total a US\$2,5 bilhões, e só nos cinco primeiros meses de 1999 essas importações atingiram US $\$ 1,5$ bilhão. Quando a soma engloba os componentes eletrônicos, a diferença entre as importações e exportações fica maior ainda: no ano passado, todos os equipamentos de telecomunicações e informática representaram compras no exterior no valor de US $\$ 5,177$ bilhões, enquanto as vendas do Brasil a outros países se limitaram a US\$566 milhões. Esses dados levaram a Anatel, por sugestão do governo, a aprovar uma portaria delegando competência ao Superintendente-Executivo para definir a relação dos produtos de telecomunicações passíveis de certificação. Como as empresas de telecomunicações só poderão utilizar os produtos certificados, sob pena de receber algumas das mais pesadas multas que a Anatel pode aplicar, deverá cair drasticamente a parcela do déficit comercial decorrente dessas importações ${ }^{13}$.

\section{V.2 Energia elétrica}

A privatização do setor elétrico brasileiro começou a delinear-se em 1993, quando as empresas do setor foram incluídas no Programa Nacional de Desestatização (PND). O relatório do estudo encomendado pelo governo federal à consultoria Coopers \& Lybrand para orientar a privatização do setor, entretanto, fazia escassa menção à $\mathrm{P} \& \mathrm{D}$ e ao papel do CEPEL no novo ambiente, tendo em vista a enorme complexidade do setor e de seu processo de privatização ${ }^{14}$.

A lei de agosto de 1997 que estipulou as bases

\footnotetext{
13 A decisão põe nas mãos da Agência a decisão em torno da divergências de opiniões entre a Anatel e o BNDES, de abril de 1999, sobre o mínimo de equipamentos que as concessionárias de telefonia devem contratar de empresas domésticas com tecnologia nacional. A ANATEL defendia que a exigência fosse de $10 \%$ de equipamento produzido no país, no caso da telefonia fixa local, e de $5 \%$ para a nacional. Já o BNDES, designado o responsável pela privatização da Telebrás, recomendava à Agência que o percentual fosse de, respectivamente, de $20 \%$ e $10 \%$ (Gazeta Mercantil, 16.abr.1998).

14 Era aí sugerido que o financiamento da pesquisa básica, sem uma definição específica do que significasse isso, fosse realizado por um Conselho Nacional de Pesquisa e Desenvolvimento, administrado por entidades de serviços do setor. Os recursos viriam de uma taxa para pesquisa básica e desenvolvimento cobrada sobre as vendas para o consumidor final ou de $0,5 \%$ sobre as vendas totais do sistema. Parte dessa receita financiaria os programas de conservação de energia do PROCEL e outra parcela iria para a pesquisa. Toda a pesquisa com fins comerciais seria financiada diretamente pela empresa interessada. Ademais, as empresas seriam estimuladas a gastar em $\mathrm{P} \& \mathrm{D}$ em qualquer centro de sua escolha e tal gasto seria levado em consideração pela ANEEL ao estabelecer a fórmula tarifária. Nesse quadro o CEPEL seria uma organização que disputaria recursos com outras. Continuaria vinculado à Eletrobrás, que juntamente com suas quatro principais subsidiárias que serão privatizadas, continuariam assegurando seu funcionamento durante um período de transição, ao cabo do qual o CEPEL deveria obter um mínimo de $50 \%$ de seu orçamento através de contratos comerciais (COOPERS \& LYBRAND, 1997).
} 
da Política Energética Nacional, entretanto, não fez uma menção específica ao papel da $\mathrm{P} \& \mathrm{D}$, tendo mencionado a utilização de "fontes alternativas de energia, mediante o aproveitamento econômico dos insumos disponíveis e das tecnologias aplicáveis", "[a ampliação da] competitividade do país no mercado internacional" e "[a proteção do] meio-ambiente e promover a conservação de energia" (Lei n. 9 478, de 6 de agosto de 1997). Já o decreto de criação da Agência Nacional de Energia Elétrica (ANEEL), de outubro de 1997, menciona entre suas competências "estimular e participar das atividades de pesquisa e desenvolvimento tecnológico necessários ao setor de energia elétrica" (Decreto n. 2 335, de 6 de outubro de 1997). Como mostrado no Quadro 3, a única taxa dirigida no setor até o presente momento com relação ao desenvolvimento tecnológico diz respeito à conservação de energia.

A ANEEL herdou a sede em Brasília, o pessoal e as dívidas do extinto Departamento Nacional de Águas e Energia Elétrica (DNAEE), mas foi autorizado a contratar sem licitação até 155 especialistas para o exercício de suas funções reguladoras pelos 36 meses iniciais. Seu orçamento anual, de R \$200 milhões, é proveniente da Taxa de Fiscalização de Serviços de Energia Elétrica, cobrada de empresas do setor elétrico. Sua estrutura é constituída de uma diretoria, uma procuradoria-geral e uma superintendência de processos organizacionais. A diretoria, composta por um Diretor-Geral e 4 diretores, é nomeada pelo Presidente da República e aprovada pelo Senado Federal.

A Eletrobrás, que antes da reestruturação do setor assegurava o secretariado da grande maioria das funções do setor, ficou de modo geral restrita ao financiamento, e, na parte operativa, às funções de transmissão que não serão privatizadas em um primeiro momento. Ainda restam dúvidas acerca de seu papel com relação ao Programa de Conservação de Energia (PROCEL), secretariado em grande medida pelo CEPEL. Assim a Eletrobrás será a única empresa estatal da área produtiva no setor que sobreviverá ao processo de privatização. Apesar da substancial redução em seu patrimônio, de $\mathrm{R} \$ 58$ bilhões para $\mathrm{R} \$ 20$ bilhões, será uma empresa enxuta, pois as dívidas do sistema serão assumidas pelas empresas privatizadas (Jornal do Brasil, 08.jun.1998).

QUADRO 3 - Desenvolvimento tecnológico e regulação em energia elétrica

- Decreto n. 2 335, de 6 de outubro de 1997 - institui a Agência Nacional de Energia Elétrica (ANEEL), cujo Art. $4^{\circ}$ estipula que à ANEEL compete, entre outras coisas:

I. implementar as políticas e diretrizes do governo federal para a exploração de energia elétrica e o aproveitamento dos potenciais de energia hidráulica

II. incentivar a competição e supervisioná-la em todos os segmentos do setor de energia elétrica

IX. incentivar o combate ao desperdício de energia no que diz respeito a todas as formas de produção, transmissão, distribuição, comercialização e uso da energia elétrica

XXII. estimular e participar das atividades de pesquisa e desenvolvimento tecnológico necessárias ao setor de energia elétrica

- De acordo com a cláusula específica dos Contratos de Concessão, as empresas do setor elétrico são obrigadas a aplicar anualmente em P\&D. Os primeiros contratos de geração previam o percentual mínimo de $0,25 \%$ da receita anual, enquanto para os contratos de distribuição o percentual era de 0,1\%. A Lei n. 9 991, de 24 de julho de 2000 (regulamentada pelo Decreto n. 3 867, de 16 de julho de 2001), alterou esses percentuais para investimentos mínimos e ampliou a abrangência de agentes do setor elétrico comprometidos com investimentos, abrangendo todas as empresas concessionárias, permissionárias e autorizadas do setor de energia elétrica, inclusive transmissoras. O Art. $1^{\circ}$ da Lei n. 9 991/2000 determina que as concessionárias e permissionárias do serviço público de distribuição de energia elétrica (após 31 de dezembro de 2005) apliquem anualmente o montante de, no mínimo, $0,75 \%$ da sua receita anual em $P \& D$ do setor elétrico e, no mínimo, 0,25\% em programas de eficiência energética, voltados para o uso final da energia. As concessionárias e autorizados do serviço público de geração (após $1^{\circ}$ de janeiro de 2006), os produtores independentes, bem como as concessionárias de transmissão (após celebração do contrato), ficam obrigados a aplicar, anualmente, o montante de, no mínimo, 1\% de sua receita operacional líquida em pesquisa e desenvolvimento do setor elétrico, excluindo-se, por isenção, as empresas que geram energia, exclusivamente, a partir de instalações eólicas, solares, de biomassa e pequenas centrais hidrelétricas.

- Dos recursos destinados à P\&D, $50 \%$ são destinados ao Fundo Nacional de Desenvolvimento Científico e Tecnológico (FNDCT), criado pelo Decreto-Lei n. 719, de 31 de julho de 1969 e restabelecido pela Lei n. 8 172, de 18 de janeiro de 1991, e o restante aplicado em programas desenvolvidos pelas empresas de energia elétrica, segundo os regulamentos estabelecidos pela ANEEL.

Fonte: Elaboração do autor, a partir de ANEEL (2002). 
Foi a essa forte empresa que se decidiu finalmente deixar vinculado o Centro de Pesquisas Elétricas (CEPEL), que terá que se adaptar ao longo dos próximos anos a fim de satisfazer as novas demandas da nova Eletrobrás. O CEPEL do sistema Eletrobrás foi fundado em 1974 por um grupo de empresas sócio-fundadoras: CHESF, Eletrosul, Eletronorte e Furnas. Ao longo dos anos outras empresas elétricas públicas (algumas atualmente privadas, como a Light e a Ecelsa) juntaram-se ao financiamento do CEPEL. Possui atualmente um orçamento de $\mathrm{R} \$ 42$ milhões, dos quais $22 \%$ financiado por meio de contratos externos (em 1996 eram 10\%, e menos de 5\% em 1993), e o restante pela Eletrobrás e empresas operadoras de seu sistema, federais e estaduais, assim como pelos novos sócios especiais, como a privatizada Light. Entretanto, a Light, que antes da privatização contribuía com quase $\mathrm{R} \$ 2$ milhões anuais como sócio-fundadora, diminuiu sua participação para apenas $10 \%$ desse valor, sendo que demanda $3 \%$ do mesmo em estudos específicos de laboratório e ensaios de bancada, ao invés de contribuir para os projetos cooperativos cofinanciados de médio e largo prazo (na Carteira de Projetos Institucionais) ${ }^{15}$. O CEPEL vem desde 1996 adaptando-se nos níveis organizacional e estratégico ao novo ambiente competitivo do setor elétrico. Nesse ano (1996) introduziu laboratórios temáticos de desenvolvimento e começou a implantar já desde de 1992 uma estrutura de funcionamento matricial voltada para clientes. Sua tendência é de orientar seu perfil para as novas necessidades de apoio nas áreas de transmissão e conservação de energia.

A taxa de financiamento a pesquisa e conservação de energia proposta pelos consultores (e que em certo momento foi dita ficar em $0,25 \%$ sobre as vendas de energia) não foi incorporada especificamente na lei de criação da ANEEL, ao contrário daquela de criação do CPqD. A ANEEL buscou incorporar essa taxa no contrato de concessão da primeira grande privatização do sistema, da Light, mas não obteve êxito. Já no caso da segunda grande privatização do setor, da Gerasul, a parte de transmissão ficou com a Eletrosul, integrante do sistema Eletrobrás, que continuará contribuindo para o funcionamento do CEPEL com R $\$ 600$ mil por ano, incluindo-se a

15 O CEPEL possuía em 1999 cerca de 500 empregados, dos quais 163 pesquisadores ( 88 com M.Sc. e 20 com Ph.D.). cláusula de que a concessionária gaste $0,25 \%$ do faturamento bruto em pesquisa e desenvolvimento (P\&D). Entrementes, não se estipulou se a compra de tecnologia poderia ser descontada desse valor - questão ainda a ser decidida pela ANEEL.

A ANEEL, na falta de princípios estabelecidos em lei, tem adotado uma "estratégia de varejo" para impulsionar a $\mathrm{P} \& \mathrm{D}$ no setor, juntamente com a eficiência energética. Em 1999 foram assinados 13 acordos de melhoria de $\mathrm{P} \& \mathrm{D}$ para a eficiência energética e para a conservação de energia com geradoras de energia elétrica, alguns com um forte componente de pesquisa e desenvolvimento.

A preocupação da Agência com a questão da P\&D havia começado a esboçar-se já em março de 1998, e em 1999 a ANEEL organizou um grande seminário internacional para debater o futuro a ser dado ao Laboratório de Concreto de uma empresa do sistema Eletrobrás, a Furnas, que seria privatizada no começo de 2000 - o que acabou não ocorrendo. O Laboratório, único no mundo além de um semelhante nos Estados Unidos, justificava sua existência na era de construção de grandes barragens hidroelétricas, mas, com a quase total cessação desses grandes projetos, fica difícil justificar seu orçamento anual de quase $\mathrm{R} \$ 20 \mathrm{mi}-$ lhões, coberto em apenas $15 \%$ por receitas externas.

Em julho de 2000, a ANEEL e o Ministério da Ciência e Tecnologia (MCT) fizeram instituir o CTENERG (Fundo Setorial de Energia), destinado a financiar programas e projetos na área de energia, com especial ênfase na área de eficiência energética no uso final. Esse fundo aprimora o mecanismo de incentivo a P\&D adotado pela ANEEL nos contratos de concessão, ampliando sua abrangência setorial, enfatizando a articulação entre os gastos diretos das empresas em $\mathrm{P} \& \mathrm{D}$ e a definição de um programa abrangente, que busca enfrentar os desafios de longo prazo no setor, tais como fontes alternativas de energia e a redução do desperdício (MINISTÉRIO DA CIÊNCIA E TECNOLOGIA, 2000). O CTENERG é financiado com uma parcela das taxas pagas por empresas concessionárias de geração, transmissão e distribuição de energia elétrica, num percentual variável de $0,75 \%$ a $1 \%$ da receita operacional líquida.

A privatização do setor de energia elétrica deve gerar receitas para o Estado da ordem de US\$50 bilhões, quase o dobro do realizado com telecomunicações. A falta de capacidade de inves- 
timento do Estado (taxa de investimento aquém da depreciação do capital) levou a sérias ameaças de falta de energia elétrica no país nos últimos anos. As empresas privatizadas até 1999 investiram a um ritmo mais alto do que no passado. Assim a Light e a Cerj, empresas privatizadas no Estado do Rio de Janeiro (respectivamente em dezembro e agosto 1996), investiram em 1997 cerca de 5 vezes mais do que investido em média nos 5 anos anteriores (Jornal do Brasil, 07.fev.1998). Entretanto, a especificidade desses investimentos, bem como a ausência de uma coordenação no marco de um planejamento energético estruturado, que buscasse alinhar os interesses dos diferentes atores organizacionais e institucionais do setor energético - geradores, transmissores e distribuidores -, contribuíram em parte para o racionamento de energia implantado no ano de 2001, levando também ao questionamento da estrutura de governança do modelo regulatório existente.

A ANEEL tem buscado também disciplinar os termos da transferência de tecnologia no setor. A espanhola Iberdrola, que assumiu o controle da Companhia de Eletricidade da Bahia (COELBA), postulou querer cobrar uma taxa de $4 \%$ da receita líquida a título de transferência de tecnologia ou de prestação de serviços. Mas a ANEEL vetou, por a considerar inadequada, entendendo que, ao assumir o controle de uma companhia nacional, a empresa estrangeira tem por princípio transferir know-how, critério básico da seleção, de maneira natural e não por força de um contrato (Gazeta Mercantil, 08.ago.1998).

\section{V.3 Petróleo e gás}

A companhia estatal de petróleo, Petrobrás, tinha, desde sua criação nos anos cinqüenta, uma pequena unidade de pesquisa e treinamento, que levava a cabo projetos em cooperação com Universidades. Sua meta era treinar mão de obra em prospecção e exploração de petróleo para a emergente indústria de petróleo. Foi somente em 1966 que se criou formalmente seu centro de P\&D, o Centro de Pesquisas e Desenvolvimento (CENPES). O CENPES teve um crescimento real principalmente a partir dos anos setenta, quando começou a utilizar engenharia reversa na tecnologia importada pela Petrobrás. Ao final daquela década o CENPES tinha diversificado o escopo de suas pesquisas em petroquímica e engenharia básica. Os choques do petróleo forçaram-no a revisar suas crescentes prioridades, afastando-se do modelo de substituição de importações, e direcionando-se para a prospecção e exploração de petróleo, alinhado com a nova prioridade de sua controladora Petrobrás de busca de auto-suficiência na produção de petróleo. Ao mesmo tempo, face à magnitude do desafio a ser enfrentado, o CENPES procurou estreitar seus laços com outras instituições de pesquisa, principalmente Universidades e fornecedores da Petrobrás, abrindo sua estratégia de capacitação tecnológica. Na seqüência desses esforços, a Petrobrás realizou uma série de descobertas de petróleo em águas profundas, na bacia de Campos, que requereram tecnologias de exploração e produção sofisticadas e não disponíveis no mercado internacional. Assim, de meados dos anos oitenta em diante, o CENPES perseguiu a inovação tecnológica voltada para atender a esses objetivos estratégicos. No início dos anos noventa, graças às pesquisas do CENPES, a Petrobrás dominava cerca de 60 tecnologias no espectro da indústria de petróleo, com um foco em refino (20) e exploração (10).

Em 1997, o CENPES tinha um orçamento de US\$202 milhões para P\&D e engenharia - cerca de $90 \%$ dos gastos totais da Petrobrás nessa função. Desse total, US $\$ 16,7$ milhões eram gastos em projetos de pesquisa cooperativos com 24 Universidades e centros de pesquisa. O CENPES também tinha 71 projetos de pesquisa multiclientes com centros de pesquisa e companhias estrangeiras em um total de cerca de US\$5 milhões de dólares, incluindo mesmo 3 centros de P\&D de companhias estatais de petróleo latino-americanas e da Noruega ${ }^{16}$.

O setor de petróleo e gás foi até o presente um dos menos afetado pelas reformas regulatórias. Ainda que tenha tido dois segmentos downstream ${ }^{17}$

\footnotetext{
16 Também conduziu 3 programas estratégicos de pesquisa corporativa nas áreas de inovação tecnológica na exploração de águas profundas e ultra-profundas (PROCAP 2000), recuperação de petróleo (PRAVAP) e estratégias de refino (PROTER). Em paralelo, conduziu programas de pesquisa tecnológica para otimizar tecnologia offshore para exploração, perfuração e produção (com benefícios acumulados até o presente da ordem de US $\$ 1$ bilhão) e lançou um programa tecnológico de dutos. O PROCAP tem sido realizado por uma rede de pesquisa cooperativa desde seu início em 1986. No início dos anos 90, 12 universidades e centros de pesquisa (a maioria no estado do Rio de Janeiro) participavam de 33 projetos.

17 Setores produtores de bens derivados dos produtos primários.
} 
privatizados no início dos anos noventa, com um impacto considerável na em sua inovação: os setores de petroquímica e fertilizantes. A privatização das subsidiárias da Petrobrás no segmento de petroquímica teve, de acordo com observadores, um impacto negativo na capacidade nacional de inovação do segmento. O CENPES reduziu drasticamente suas equipes de pesquisa na área, provocando o desmantelamento de equipes associadas de pesquisa em firmas regionais e centros de pesquisa universitários e em petroquímica.

Ainda assim, o mercado para exploração, produção e distribuição de petróleo e gás foi inteiramente aberto à competição (em alguns segmentos já existia anteriormente uma competição limitada) pela Lei n. 9 478, de agosto de 1997, que também criou a Agência Nacional de Petróleo (ANP).

Conforme determinado na Lei - particularmente em seu Artigo 49 e na cláusula 22 - sobre participação governamental nos royalties - e em dramático contraste com os setores de telecomunicações e energia elétrica -, a ANP fez aprovar pelo Executivo, já em agosto de 1998, as regras de implementação de itens relativos à promoção do desenvolvimento tecnológico e de treinamento de recursos humanos para o setor. Essa relativamente rápida aprovação foi possível pela forte mobilização de interesses políticos do estado do Rio de Janeiro, o maior produtor de petróleo do país ( $70 \%$ da produção nacional) e o estado com o maior número de firmas industriais e de serviços e de Universidades e centros de pesquisa na área de petróleo. A estes veio juntar-se o interesse e o poder de influência da própria Petrobrás, que, por meio da criação do Fundo Setorial de Petróleo (CTPETRO), pôde contar com um subsídio para suas atividades de $\mathrm{P} \& \mathrm{D}$; e, com o Programa de Recursos Humanos da ANP, pode contar com o financiamento governamental para treinamento de recursos humanos de que necessita.

Primeiro, a bancada federal do partido governista (PSDB), liderada pelo Governador do estado do mesmo partido na época, assegurou a inclusão da cláusula relevante na Lei. Em seguida, o antigo Secretário Estadual de Ciência e Tecnologia do Estado do Rio de Janeiro, professor universitário na área de tecnologia de petróleo e aliado político do então governador, foi nomeado para ser um dos 5 membros do Corpo Diretor da ANP diretamente pelo Presidente da República, sem neces- sidade de aprovação pelo Congresso. Em terceiro lugar, todas as grandes Universidades de pesquisa e centros de $\mathrm{P} \& \mathrm{D}$ com atividades relacionadas à indústria de petróleo criaram rapidamente a Rede de Ciência e Tecnologia do Petróleo (Redepetro). Esse grupo de interesse realizou um levantamento das capacidades disponíveis e apresentou-se como interlocutor preferencial da ANP e das companhias de petróleo no que dizia respeito ao treinamento e $\mathrm{P} \& \mathrm{D}$ em todos os segmentos da indústria petrolífera. Finalmente, o conjunto dessas forças políticas pressionou o Executivo para direcionar uma parcela dos royalties do petróleo para atividades de $\mathrm{P} \& \mathrm{D}$, por meio do Programa de Apoio a Pesquisa Científica e Desenvolvimento Tecnológico na Indústria de Petróleo, de acordo com os dispositivos do Artigo 49 da Lei n. 9478.

Estima-se que o programa mais tarde conhecido como CTPETRO (Programa Nacional de Ciência e Tecnologia do Setor de Petróleo e Gás Natural), gerará cerca de $\mathrm{R} \$ 900$ milhões nos próximos 5 anos de novos fundos para programas de pesquisa na área, a partir de 2000, administrados pelo Ministério da Ciência e da Tecnologia, com apoio técnico da ANP. Já em 1999-2000 foram aplicados cerca de $\mathrm{R} \$ 242$ milhões em 696 projetos de duas dezenas de instituições. $\mathrm{O}$ CTPETRO é administrado por um organismo vinculado ao MCT, a FINEP, através de seu Fundo Nacional de Desenvolvimento Científico e Tecnológico (FNDCT), e é coordenado por um Comitê Gestor constituído por nove membros, inclusive dois representantes da comunidade científica, nomeados em conjunto pelo Ministério da Ciência e Tecnologia, pela ANP e pelo Ministério de Minas e Energia. A regulamentação do CTPETRO estipulou que $25 \%$ da percentagem de royalties que ultrapassar $5 \%$ da produção nacional (royalties pagos aos estados produtores estão limitados a 5\%) serão transferidos ao FNDCT para financiar projetos na área. Ademais, determinou-se que $40 \%$ do valor arrecadado deve ser gasto em instituições de ensino e pesquisa nas regiões Norte e Nordeste.

Além de outras provisões menores de fundos para pesquisa básica em geologia e geofísica a serem coordenadas pela ANP e pelo Ministério das Minas e Energia, a ANP também incluiu nos contratos de concessão de áreas de exploração e produção de petróleo e gás uma cláusula determinando que, no caso de a "participação especial" (um royalty adicional imposto em poços com ele- 
vada produção ou em campos de elevado retorno) igualar ou exceder $10 \%$, o valo de $1 \%$ do faturamento baseado na produção bruta da companhia seja investido em projetos e programas de P\&D. Desse total, $50 \%$ no mínimo devem ser investidos em serviços de pesquisa e desenvolvimento em Universidades e centros de P\&D credenciados pela ANP. Estima-se que no período 2001-2004 essas empresas despenderão cerca de $\mathrm{R} \$ 586$ milhões em atividades de $\mathrm{P} \& \mathrm{D}^{18}$.

A ANP também criou seu próprio Programa de Recursos Humanos para o Setor de Petróleo e Gás, inicialmente com fundos próprios, e mais recentemente financiado com fundos do CTPETRO. O PRH visa a formar profissionais demandados pela indústria e oferece cerca de 809 bolsas e pagamento de taxa de bancada para programas de formação nos níveis de graduação, mestrado e doutorado em áreas de interesse para a indústria de petróleo e gás. Mais recentemente, o PRH também iniciou a concessão de bolsas para alunos de escolas técnicas, porém financiadas com recursos próprios. $\mathrm{O}$ desempenho dos programas que fazem parte do PRH é monitorado regularmente e avaliado anualmente, para assegurar que o treinamento dispensado aos alunos vá realmente ao encontro da demanda da indústria.

A Petrobrás, que até recentemente detinha o monopólio na exploração, desenvolvimento e produção de petróleo e gás no país, bem como um monopólio virtual no segmento de refino $(97,3 \%)$, provavelmente terá suas parcelas de mercado reduzidas. Entretanto, ela será a melhor capacitada para tirar vantagem dos resultados dos investimentos em treinamento e P\&D dos programas gerados pela ANP nos próximos anos, constituindo-se um subsídio velado às suas atividades nessas áreas.

A ANP também tem sido ativa na proteção do desenvolvimento da tecnologia e da indústria brasileira de bens de capital. Estimulou,

\footnotetext{
18 Deve-se levar em consideração que esse valor está subestimado, na medida em que foi calculado com base em um preço de petróleo inferior ao atual e em taxas de câmbio anteriores à desvalorização da segunda metade de 2001.
}

conjuntamente com a Federação das Indústrias do Rio de Janeiro (FIRJAN), a criação da Organização Nacional da Indústria de Petróleo (ONIP), que tem por missão assegurar a participação de fornecedores nacionais para a indústria de petróleo da expansão do mercado brasileiro de petróleo. A ONIP foi organizada segundo o molde de organizações semelhantes criadas no Reino Unido e na Noruega por ocasião do desenvolvimento da exploração no Mar do Norte, e constitui-se em um interlocutor privilegiado para os esforços da ANP em auxiliar a indústria de capital nacional. Paradoxalmente, o estudo que deu origem à criação da ONIP foi elaborado pelo Departamento de Economia da PUC-Rio, templo da economia neoliberal no país. A ONIP pretende ser um catalisador cooperativo entre firmas de prospecção, exploração e distribuição, fornecedores nacionais, agências governamentais, grupos de interesse patronais e de trabalhadores, agências de financiamento e instituições de ensino e pesquisa. Nesse sentido, uma de suas primeiras atividades foi a realização de um levantamento da capacidade da indústria nacional de equipamentos e serviços para a indústria de petróleo. A partir desse estudo, a ONIP elaborou uma lista de equipamentos e serviços passíveis de serem comprados pelas empresas de petróleo de fornecedores nacionais. Uma arguta observadora do debate sobre política industrial no país chamou a ONIP de "um exemplo a ser seguido", considerando-a de uma das "mais brilhantes idéias que surgiram na área industrial no país" (PRADO, 1999).

Em outro fronte, o Ministério das Minas e Energia estipulou que futuros editais da Petrobrás para construção de navios-tanque, plataformas de exploração e equipamentos correlatos terão que conter uma cláusula determinando que sua produção seja feita no estado do Rio de Janeiro, até mesmo por empresas estrangeiras estabelecidas no país. Estima-se que a demanda por esses equipamentos pela indústria de petróleo e gás nos próximos 10 anos atingirá cerca de US $\$ 10$ bilhões, devido à quebra do monopólio da Petrobrás e a conseqüente abertura da exploração e produção para as empresas privadas do setor (Jornal do Brasil, 05.out.1998). 
QUADRO 4 - Desenvolvimento tecnológico e regulação em petróleo e gás

\begin{tabular}{|l|}
\hline Desenvolvimento tecnológico e regulação na Lei do Petróleo e Gás \\
\hline - $25 \%$ do valor que exceder a $5 \%$ dos royalties da produção de petróleo e gás natural \\
- $\quad$ Revisão de US $\$ 300$ milhões (1999 a 2003) \\
- $\quad$ Destinado administrados univelo MCT/FINEP/FNDCT, com apoio técnico da ANP \\
indústria de petróleo \\
- A ANP incentiva a formação de redes de pesquisa, com a participação de empresas \\
\hline Investimento em P\&D por parte das empresas concessionárias \\
\hline - Cláusula nos Contratos de Concessão para Exploração e Produção de Petróleo e Gás Natural que prevê: \\
1. Investimento de $1 \%$ sobre a produção dos poços com incidência de Participação Especial \\
2. No mínimo $50 \%$ deverão ser investidos na contratação de projetos de novos produtos e processos junto a ins- \\
- tituiçães de P\&D, credenciadas pela ANP. \\
Previsão de US $\$ 200$ milhões (1999 a 2003)
\end{tabular}

Fonte: Fernández y Fernández (1999).

\section{CONCLUSÕES}

Os mecanismos institucionais neonacionalistas de promoção da área de C\&T desenvolvidos pelas agências reguladoras vem criando um novo padrão de formação de políticas públicas. Ocorre então um isomorfismo institucional (DI MAGGIO \& POWELL, 1991), no qual burocratas empreende- dores buscam copiar não só a forma (fundos), mas também a estratégia de formação da política pública para a área específica. Essa estratégia tem como fatores principais a busca de um apoio federativo no Congresso em troca de um direcionamento de benefícios para regiões menos favorecidas pelos dispositivos até então existentes.

QUADRO 5 - Orçamento dos fundos setoriais do Ministério de Ciência e Tecnologia, em 2001 (em R\$ milhões)

\begin{tabular}{|c|c|c|c|}
\hline \multirow{2}{*}{ Fundos setoriais } & \multirow{2}{*}{ Orçamento 2001} & \multicolumn{2}{|c|}{ Estimativas de arrecadação } \\
\hline & & 2002 & 2003 \\
\hline CTPETRO & 151,1 & 159,0 & 167,0 \\
\hline CTINFO & 44,0 & 50,0 & 55,0 \\
\hline CTENERG & 80,0 & 155,0 & 163,0 \\
\hline CTHIDRO & 26,9 & 51,0 & 56,0 \\
\hline CTMINERAL & 27,0 & 8,0 & 16,0 \\
\hline CTTRANSPO & 8,0 & 9,0 & 11,0 \\
\hline CTESPACIAL & 5,4 & 5,4 & 5,4 \\
\hline $\begin{array}{l}\text { Universidade-empresa } \\
\text { (Verde-amarelo) }\end{array}$ & 192,0 & 192,0 & 192,0 \\
\hline INFRA-ESTRUTURA $^{19}$ & 138,6 & 126,0 & 133,0 \\
\hline FUNTTEL 20 & 239,05 & 176,05 & 190,6 \\
\hline TOTAL & 887,75 & 931,45 & 988,95 \\
\hline
\end{tabular}

Fonte: Ministério das Comunicações (2001b).

Na mesma linha, ao longo dos últimos dois anos e apoiado no sucesso de obtenção de recursos

\footnotetext{
19 O volume de recursos disponível para 2001 incluía parcela arrecadada em 2000.

20 Sob responsabilidade do Ministério das Comunicações.
}

para a área de C\&T obtido pelo CTPTETRO, o próprio Ministério da Ciência e Tecnologia (MCT) estabeleceu alianças com diferentes ministérios e organismos regulatórios, ao patrocinar a criação de cinco novos fundos setoriais (além daqueles acima discutidos) - para recursos hídricos, transportes terrestres, recursos minerais, espacial 
e tecnologia da informação - e dois fundos horizontais - Cooperação Universidade-Empresa (Verde-Amarelo) e infra-estrutura. A expectativa é de que em 2002 serão 14 fundos em operação com previsão de investimentos da ordem de $\mathrm{R} \$ 1$ bilhão. Em dezembro de 2001 foi sancionada uma lei de criação de quatro novos fundos setoriais de Desenvolvimento Científico e Tecnológico em saúde, agronegócios, biotecnologia e aeronáutica. Prevê-se que, juntos, os novos fundos façam investimentos da ordem de R\$520 milhões, em 2002. De acordo com o projeto, os novos fundos serão financiados por recursos provenientes da adequação na base de cálculo da contribuição, criada em 2001, para financiar o Fundo VerdeAmarelo. Como já ocorre com os demais fundos, $20 \%$ dos recursos serão repassados ao Fundo Setorial de Infra-Estrutura. Ainda de acordo com o Projeto de Lei, no mínimo 30\% dos recursos destinados a cada um dos novos fundos deverá ser alocado em projetos desenvolvidos por empresas e instituições de pesquisa sediadas nas regiões Norte, Nordeste e Centro-Oeste, como já ocorre com os demais fundos setoriais.

Por exemplo, recentemente, para aprovar a renovação da Lei de Informática - que concede benefícios para realização de $\mathrm{P} \& \mathrm{D}$ na área a partir de isenções fiscais para empresas do setor -, o Ministério de Ciência e Tecnologia valeu-se dessa estratégia, tendo como resultado que os termos dos benefícios para as regiões Norte, Nordeste e Centro-Oeste foram mais favoráveis (uma vez que a indústria está localizada na região Sudeste, principalmente no estado de São Paulo), bem como com prazos de concessão mais largos (MINISTÉRIO DA CIÊNCIA E TECNOLOGIA, 2001a). Ademais, dos gastos previstos no CTINFO (Fundo Setorial para a Tecnologia da Informação), $7 \%$ do faturamento das empresas do segmento que deverá somar R $\$ 70$ milhões em 2000 -, do montante de $40 \%$, terão de ser aplicados nas regiões Norte, Nordeste e Centro-Oeste. Na mesma linha, o MCT falava em perseguir após a regulamentação da Lei der Informática aprovada no início de 2001 (o que efetivamente ocorreu por meio do Decreto de 17/12/2001 que fixou as alíquotas do Imposto sobre Produtos Industrializados (IPI) para o setor e incorporou os subsídios previstos ${ }^{21}$ ), uma política que viria a sobretaxar

21 As alíquotas fixadas pelo decreto são de $15 \%$ para bens finais, de $10 \%$ para peças e de $2 \%$, de $5 \%$ e de $8 \%$ para com- as importações de softwares com mudanças na isenção do IOF hoje em vigor, para gerar um fundo destinado a financiar de modo sustentável o desenvolvimento da indústria de software nacional ${ }^{22}$. O Secretário Nacional de Política de Informática, Roberto Pinto Martins, vinculado ao MCT, calcula que $5 \%$ desse mercado representa uma receita para o fundo de US\$50 milhões. Finalmente, um Projeto de Lei (n. 5 584/2001) aprovado pelo Senado em dezembro de 2001, também cria instrumentos de estímulo ao investimento em pesquisa e desenvolvimento no setor privado, ao destinar ao Fundo VerdeAmarelo, além dos recursos da contribuição das empresas ao fazerem remessas ao exterior, um aporte adicional de recursos do Tesouro Nacional. A cada ano, a renúncia fiscal do setor privado de informática, referente ao recolhimento do Imposto sobre Produtos Industrializados (IPI), reduz-se, mas uma parte, correspondente ao montante a que tem direito a União (43\% do IPI) será destinada ao Fundo Verde-Amarelo. Em 2002, esses recursos significarão um aporte adicional no valor de $\mathrm{R} \$ 70$ milhões. A previsão é de que em oito anos, apenas com os recursos provenientes desse mecanismo, o Fundo Verde-Amarelo aplique $\mathrm{R} \$ 2$ bilhões em projetos de apoio à pesquisa em instituições públicas e no setor privado. Esses recursos tornarão mais atraentes os incentivos dos Programas de Desenvolvimento Tecnológico Industrial (PDTI) e Programas de Desenvolvimento Tecnológico Agropecuário (PDTA), uma vez que poderão subvencionar as empresas que

ponentes. $\mathrm{O}$ decreto restaura as alíquotas que vigoraram até dezembro de 2000 com a antiga Lei de Informática. Durante o período em que esteve em discussão a proposta da nova lei, vigorou emergencialmente uma alíquota de $2 \%$ para o setor (MINISTÉRIO DA CIÊNCIA E TECNOLOGIA, 2002).

22 A importação de software tem crescido mais de 50\% ao ano no país. O Brasil importou US\$70 milhões em 1978, e 1998 chegou a importar US\$700 milhões. A previsão para 1999 era de que a importação de software atingiria US\$1 bilhão. Esse mercado movimentou US\$1,8 bilhão no Brasil, em 2001, segundo dados da International Data Corporation local. Para 2002, a expectativa é um crescimento de 5,1\%, totalizando US $\$ 1,89$ bilhão. Estima-se que a exportação de software em 2001 tenha sido da ordem de 115 milhões de dólares. A meta para os próximos três anos é ampliar em $30 \%$ as exportações de programas, alcançando 130 milhões de dólares. Até 2005 o faturamento das empresas do setor deve chegar a US\$270 milhões (MINISTÉRIO DA CIÊNCIA E TECNOLOGIA, 2002). 
estiverem desenvolvendo programas de inovação tecnológica.

A reforma regulatória nessas três áreas criou novas agências com mandatos amplos e distintos, inclusive para desenvolvimento de capacidade tecnológica. Como demonstrado acima, a capacidade de definição e implementação dos programas de inovação tecnológica e de formação de recursos humanos varia consideravelmente entre elas. Em petróleo e gás, por exemplo, a implementação desses programas avançou mais rapidamente e foi mais longe, em função da visão mobilizadora de seus técnicos e da pressão estrutural da empresa estatal remanescente, Petrobrás, para obter subsídios indiretos para suas atividades de P\&D. Já o setor de energia elétrica avançou menos devido à ausência de um claro mandato da Agência setorial, decorrente em parte da ausência de uma massa crítica de técnicos em seu corpo diretor com o cabedal profissional e acadêmico apropriado, moldador de suas percepções do escopo e do limite da política pública para regulação (GRINDLE \& THOMAS, 1991), capaz de desenvolver e sustentar tal visão desenvolvimentista como parte integrante do mandato da ANEEL.

Assim, sugere-se que o avanço dos programas de promoção da inovação tecnológica, e até mesmo da defesa da indústria brasileira nacional, está de certa forma correlacionado ao nível de treinamento e experiência acadêmica dos conselheiros de cada agência. Assim, a ANP - cujas atividades têm sido mais profundas e extensas nesse sentido -, possui o quadro de conselheiros com maior preparo e experiência acadêmica. No outro extremo, a ANATEL, que até o momento pouco avançou nesse sentido, tem os quadros menos titulados e com menor experiência acadêmica e/ou de pesquisa, relativamente às outras agências.

QUADRO 6 - Nível de formação dos conselheiros das agências regulatórias, por grau de estudo e por tipo de escola freqüentada 23

\begin{tabular}{|l|c|c|c|c|c|}
\hline \multirow{2}{*}{} & \multicolumn{5}{|c|}{ Educação superior } \\
\cline { 2 - 6 } & Graduação & Especialização & Mestrado & Doutorado & Pós-doutorado \\
\hline ANATEL & 5 & 1 & 1 & 1 & - \\
\hline ANEEL & 5 & 1 & 2 & 1 & 1 \\
\hline ANP & 5 & 1 & 4 & 2 & 1 \\
\hline
\end{tabular}

\begin{tabular}{|l|c|c|c|c|c|}
\hline \multirow{2}{*}{} & \multicolumn{3}{|c|}{ Graduação } & \multicolumn{3}{c|}{ Pós-graduação } \\
\cline { 2 - 6 } & Pública & Privada & Brasil pública & Brasil privada & Exterior \\
\hline ANATEL & 1 & 4 & - & 1 & 3 \\
\hline ANEEL & 5 & - & 3 & 1 & 1 \\
\hline ANP & 2 & 3 & 3 & 3 & 2 \\
\hline
\end{tabular}

Fonte: Elaboração do autor, a partir de dados das agências disponíveis em 1999.

No futuro próximo, o acirramento da competição e um mandato governamental para reconcentrar seu foco estratégico na exploração e produção de petróleo poderia induzir a Petrobrás a reduzir o nível de apoio aos esforços de inovação de empresas fornecedoras de equipamento de capital brasileiro, na medida em que aumentaria o escopo e o volume de sua demanda por equipamentos e serviços de alta qualidade em um prazo menor, em favor

23 Deve-se observar que alguns conselheiros possuem mais de um título de graduação e/ou pós-graduação. de programas de desenvolvimento interno para o mercado brasileiro. Essa função seria, em princípio, assumida pelo Estado, por meio de programas da ANP e de outros esforços governamentais, seguindo a formulação genérica proposta para reformas do Estado por Przeworski (1996).

Essas mudanças paradigmáticas na política pública têm tido um profundo impacto no padrão emergente de política de inovação e industrial no Brasil. Primeiro, elas reforçam um dos seus pilares ausentes - a firma -, reforçando substantivamente seu elo fraco - a cooperação Universidade-indús- 
tria. Convergindo para uma tendência internacional, companhias estrangeiras estão estabelecendo laboratórios de P\&D no país, assim como laboratórios corporativos para Universidades (Correio da Unesco, 1999), induzidos pela diversidade do mercado doméstico e pelo potencial de crescimento gerado pela liberalização. Em segundo lugar, à medida que a indústria torna-se mais ativa, em contraste com as Universidades, na formação da política nacional de inovação, as relações Universidade-indústria passarão por uma grande transformação em seus escopo e regras. Em terceiro lugar, ao trazer a firma resolutamente para o centro da política de inovação, essas mudanças induziram a criação de um grande número de instituições ditas "organizações-ponte", que atuam como mediadoras e construtoras de confiança e de tradutoras de interesses, refletindo uma inovação institucional em uma linha próxima a um híbrido de neocorporatismo (NELSON, 1996; SNYDER, 1999, p. 198ss). Ao reduzir as barreiras culturais e estruturais que preveniram o aprofundamento produtivo dessas relações no passado, as organizações-ponte carregam em si a promessa de acelerar o ritmo e aumentar a densidade dessas relações entre os diferentes pilares, engrossando o caldo de cultura da inovação no país.

Em outras palavras, as mudanças provocadas nos próprios atores da política industrial e de inovação, novos e velhos, e em suas relações com a política de liberalização e com a reforma regulatória, potencialmente estimulam essa política a incorpora um novo modo de aprendizado-por-monitoramento (SABEL, 1994). Esse é um modo pelo qual a confiança é constantemente recriada por meio do monitoramento das ações pelos parceiros, e levam em seguida a uma avaliação contínua das expectativas crescentes dos atores - que, por sua vez, poderiam finalmente alimentar o sistema brasileiro de inovação com produtos socialmente relevantes e uma produtividade econômica proficiente.

Em questões de inovação, como em outras áreas mais centrais do processo regulatório, a questão-chave continua aberta: se as relações entre agências e o meio empresarial tornar-se-ão cooperativas ou conflitivas, com impactos importantes na dinâmica do sistema (VOGEL, 1986; OECD, 1998). A maneira como a reforma regulatória vai afetar no longo prazo o padrão de modernização da indústria brasileira pode ser crítico para a formulação e implementação de uma estratégia competitiva sustentável de longo prazo. A emergência de uma perspectiva conflitiva pode reabrir conflitos passados baseados em políticas protecionistas; já uma perspectiva cooperativa que gere um jogo de soma positiva para a inovação no país é, assim, mais promissora. A flexibilidade institucional já demonstrada pela ANP em algumas de suas decisões relativas ao setor empresarial pode vir a ser crítica. Entretanto, outras agências reguladoras - como a ANATEL - têm proclamado que irão primeiramente aderir ao modelo inicial, o que poderia eventualmente gerar conflitos (LEVY \& SPILLER, 1996; VOGEL 1996).

Ao final, pode-se afirmar que o Brasil ainda possui uma experiência de política pública limitada no relacionamento entre regulação e inovação. A política para inovação que as instituições regulatórias têm implementado continua, de modo geral, aprisionada na busca dos ícones santos de aumento agregado de gastos e desenvolvimento de fatores de oferta. Elas ainda desdenham de tendências paradigmáticas emergentes no conhecimento de inovação e de política de pesquisa, tais como o conhecimento da demanda, a avaliação por resultados e a integração de apoio a PMEs.

Do ponto de vista teórico, a análise aqui desenvolvida sugere a confirmação de que mudanças de estruturas de governança permitem que grupos de pressão não-tradicionais, como pesquisadores e acadêmicos, adquiram maior influência no processo de formação de políticas públicas. Isso é particularmente válido para o caso de agências reguladoras nas quais os especialistas fazem-se necessários para o cumprimento das missões, e, assim, detêm maior poder relativo e maior capacidade de negociar políticas públicas "inovadoras" ${ }^{24}$. Isso confirma, em parte, a hipótese levantada por Snyder (1998), de que o vazio criado pela reforma regulatória fornece a políticos oportunidades para expandir sua autoridade e a de seus aliados por meio da re-regulação da economia

\footnotetext{
24 "As demandas administrativas do exercício da normatividade [...] são melhor atendidas por organizações flexíveis e altamente especializadas que gozem de autonomia considerável no processo de tomada de decisões: as agências reguladoras" (MAJONE, 1999, p. 19); “Os especialistas e os reguladores constituem outro grupo importante de atores. A regulação depende largamente do conhecimento científico de engenharia e de economia, que, conforme já observamos, sempre foi uma fonte de legitimidade das agências reguladoras serem o repositório de conhecimentos e experiências específicos" (idem, p. 25).
} 
(ainda que o modelo de dois degraus por ele proposto aplique-se de maneira imperfeita aos casos aqui analisados, na medida em que a iniciativa no primeiro degrau parece ter partido de grupos sociais $^{25}$ ).

Contribuindo para isso está o próprio processo de globalização, que legitima politicamente o isomorfismo institucional perseguido pelos atores, ao copiarem justificativas e modelos de outros países, baseando-se nos resultados por eles obtidos em termos de promoção de emprego e de desenvolvimento econômico. Já na fase de implementação das políticas de inovação formuladas pelas agências, o arranjo federativo contribuiu sobremaneira ao proporcionar uma distribuição diferenciada dos benefícios resultantes àquelas unidades da federação críticas para aprovação final no Congresso Nacional.

No que diz respeito à análise comparativa dessa faceta da experiência brasileira com a reforma regulatória, cabe ressaltar que o baixo nível de regulação efetiva pré-existente à reforma e o desconhecimento generalizado das elites políticas das legítimas funções e missões esperadas e desejadas das agências regulatórias, permitiu que novas missões fossem instituídas por burocratas empreendedores, refletindo um claro comportamento oportunista no marco do modelo agente-principal. Ademais, a experiência dessas agências parece indicar um desvio das funções principais de agências reguladoras de outros países, ao criarem fundos sobre os quais detêm em diversos graus poder de orientação que driblam as problemáticas restrições orçamentárias que assolam instituições reguladoras em outras partes do mundo (e. $g$.

25 "Organized societal groups have a stake in how sectors are reregulated and can mobilize to support or challenge politicians' reregulation projects" (SNYDER, 1998, p. 174).
União Européia) (MAJONE, 1999, p. 16). Por outro lado, nessa mesma linha, a experiência das agências aqui analisadas parece indicar que elas não operam de maneira inteiramente autônoma em relação ao governo central, seja no desempenho de funções positivas (exemplificado pelo apoio implícito deste à formulação e implementação dos programas de apoio à inovação da ANP), seja no desempenho de funções normativas regulatórias, nas quais o governo central tem freqüentemente se imiscuído para determinar seu escopo, timing e intensidade.

No que diz respeito a transformações na economia política do desenvolvimento, proporcionadas por mudanças nas estruturas de governança aqui analisadas, o caso específico do processo de formulação e implementação de políticas para inovação pela ANP parece confirmar a possibilidade, como bem disse Monteiro (1999) referindo-se à experiência de Minas Gerais, de sobrevivência à globalização através de uma redefinição do desenvolvimentismo em nível regional, nesse caso o estado do Rio de Janeiro. Da mesma forma, Majone (1999, p. 6), concorrendo com a visão pessimista de Evans (1997) sobre o futuro da stateness, sugere que as novas estratégias de reforma regulatória perseguidas pelos países tendem a "limitar o papel do Estado intervencionista ou positivo, especialmente ao restringir seu poder de tributar e de despender". Todavia, se a curta experiência das agências regulatórias brasileiras serve de indicador, aponta para a existência da possibilidade de que essas reformas permitam ao Estado intervencionista reinventar-se, estabelecendo ao mesmo tempo um novo padrão de relacionamento Estadosociedade (e.g. ANP-ONIP), como almejado por Evans (1997, p. 86).

Recebido em 14 de fevereiro de 2002. Aprovado em 2 de abril de 2002.

Antonio José Junqueira Botelho (abotelho@dctc.puc-rio.br) é Ph.D. em Ciência Política (Política de C\&T e Política Comparada) pelo Massachusetts Institute of Technology (MIT), e Diretor de Pesquisa da Unidade de Pesquisa do Instituto Gênesis para Inovação e Ação Empreendedora da Pontifícia Universidade Católica do Rio de Janeiro (PUC-Rio).

\section{REFERÊNCIAS BIBLIOGRÁFICAS}

ALMEIDA, M. H. T. 1997. Federalismo e políticas sociais. Revista Brasileira de Ciências Sociais, São Paulo, v. 12, n. 33, p. 88-108, fev. 1998a. La política de la privatización de las telecomunicaciones en Brasil. Departamento de Ciência Política da Universidade 
de São Paulo : www.cienciapolitica-usp.br: 15.jun.2001.

1998b. Negociando a reforma : a privatização das empresas públicas no Brasil. Departamento de Ciência Política da Universidade de São Paulo : www.cienciapolitica-usp.br: 15.jun.2001.

ALMEIDA, M. H. T. \& MOYA, M. 1997. A reforma negociada : o Congresso e a política de privatização. Revista Brasileira de Ciências Sociais, São Paulo, v. 12, n. 34, p. 119-132, jun.

AZEVEDO, S. \& MELO, M. A. 1997. A política da reforma tributária : federalismo e mudança constitucional. Revista Brasileira de Ciências Sociais, São Paulo, v. 12, n. 35, p. 75-99, out.

BESNOSIK, R. I. 1995. Management of Technology in the Brazilian Power Sector. Science and Public Policy, v. 22, n. 1, p. 2-8, Feb.

BRANSCOMB, L. M. \& FLORIDA, R. 1998. Challenges to Technology Policy in a Changing World Economy. In : BRANSCOMB, L. M. \& KELLER, J. H. (orgs.). Investing in Innovation : Creating a Research and Innovation Policy that Works. Cambridge, Mass. : The MIT Press.

BRANSCOMB, L. M. \& KELLER, J. H. 1998. Towards a Research and Innovation Policy. In : BRANSCOMB, L. M. \& KELLER, J. H. (orgs.). Investing in Innovation: Creating a Research and Innovation Policy that Works. Cambridge, Mass. : The MIT Press.

COOPERS \& LYBRAND. 1997. Energy Efficiency and Research and Development. Working Paper C3. Brasília : SEN/ ELETROBRÁS. Digit.

COZZENS, S. \& WOODHOUSE. E. J. 1995. Science, Government, and the Politics of Knowledge. In : JASANOFF. S. (ed.). Handbook of Science and Technology Studies. London : Sage.

DINIZ, E. 1997. Crise, reforma do Estado e governabilidade. Rio de Janeiro : Fundação Getúlio Vargas.

ERBER, F. E. \& AMARAL, L. U. s/d. Os centros de pesquisa das empresas estatais : um estudo de três casos. s/l : s/n.
EVANS, P. 1997. The Eclipse of the State? Reflections on Stateness in an Era of Globalization. World Politics, Princeton, v. 50, n. 4, p. 62-87, Oct.

GRINDLE, M. S. \& THOMAS, J. W. 1991. Public Choices and Policy Change: The Political Economy of Reform in Developing Countries. Baltimore : The Johns Hopkins University Press.

GRINDLE, M. S. 1996. Challenging the State : Crisis and Innovation in Latin America and Africa. Cambridge, UK : Cambridge University Press.

HART, D. M. 1999. Antitrust : A "Hidden Technology Policy" in the US. Paper prepared for conference on "Civilian Technology Policy in the European Union and the United States : Recent Experiences and New Directions", occurred at Georgia Institute of Technology, Atlanta, Georgia, April 9-10. Digit.

JOHNSON, B. (org.). 1996. Serviços públicos no Brasil : mudanças e perspectivas. São Paulo : E. Blucher.

LANDI, F. R. (coord.). 1998. Indicadores de ciência e tecnologia em São Paulo. São Paulo : Fundação de Amparo à Pesquisa do Estado de São Paulo.

LATTMAN-WELTMAN, F. 1996. Economia e política na reforma do Estado. Lua Nova, São Paulo, n. 37, p. 77-92.

LEVY, B. D. \& SPILLER, P. T. (eds.). 1996. Regulations, Institutions and Commitment. Cambridge : Cambridge University Press.

MAJONE, G. 1999. Do Estado positivo ao Estado regulador : causas e conseqüências de mudanças no modo de governança. Revista do Serviço Público, Brasília, v. 50, n. 1, p. 5-36, jan.-mar.

MANZETTI, L. 2000a. Privatization South American Style. New York : Oxford University Press.

. (ed.). 2000b. Regulatory Policy in Latin America. Post-Privatization Realities. Miami : North-South Center Press.

MONTERO, A. P. 1999. Surviving Globalization by Remaking Developmentalism in Minas Gerais (Brazil). Paper delivered at the Second Meeting of the International Working Group 
on Subnational Economic Governance in Latin America and Southern Europe, occurred at São Paulo, in June 23-29. Digit.

NELSON, R. R. 1996. National Innovation Systems. In : . The Sources of Economic Growth. Cambridge, Mass. : Harvard University Press.

NUNES, E. 1998. Reforma administrativa, reforma regulatória : a nova face da relação Estadoeconomia no Brasil. Trabalho apresentado no XXII Encontro Anual da Associação Nacional de Pós-Graduação em Ciências Sociais, realizado em Caxambu, de 27 a 31.out. Digit.

OECD. 1996. Regulatory Reform and Innovation. Paris : Organization for the Economic and Cooperative Development.

1997. Co-operative Approaches to Regulation. Public Management Occasional Paper n. 18. Paris : Organization for the Economic and Cooperative Development.

PRZEWORSKI, A. 1996. A reforma do Estado. Responsabilidade política e intervenção econômica. Revista Brasileira de Ciências Sociais, São Paulo, v. 11, n. 32, p. 18-40, out.

REMMER, K. L. 1997. Theoretical Decay and Theoretical Development. The Ressurgence of Institutional Analysis. World Politics, Princeton, v. 50, n. 4, p. 34-61, Oct.

RIBEIRO, M. T. \& FAUCHER, P. 1994. O novo papel dos laboratórios públicos no contexto da reestruturação do Estado e dos mercados : o caso do Ireq (Quebec) e Cepel (Brasil). Revista de Administração Pública, Brasília, v. 28, n. 3, p.229-249, jul.-set.

RIBEIRO, M. T. 1994. CEPEL. Desenvolvimento de capacidade tecnológica no setor elétrico. Rio de Janeiro. Tese (Doutorado em Economia da Inovação). Instituto de Economia
Industrial, Universidade Federal do Rio de Janeiro.

SABEL, C. F. 1994. Learning by Monitoring : The Institutions of Economic Development. In : SMELSER, N. J. \& SWEDEBERG, R. (eds.). The Handbook of Economic Sociology. Princeton : Princeton University Press.

SANTOS, F. G. M. 1997. Dinâmica congressual e regulação econômica. O caso da lei portuária. Revista Brasileira de Ciências Sociais, São Paulo, v. 12, n. 34, p. 133-146, jun.

SLAUGHTER, S. \& RHOADES, G. 1996. The Emergence of a Competitiveness Research and Development Policy Coalition and the Commercialization of Academic Science and Technology. Science, Technology \& Human Values, Blacksburg (Virginia), v. 21, n. 3, July.

SNYDER, R. 1999. After Neoliberalism. The Politics of Reregulation in Mexico. World Politics, Princeton, v. 51, n. 1, p. 173-204, Jan.

SOUZA, C. 1998. Intermediação de interesses regionais no Brasil : o impacto do federalismo e da descentralização. Dados, Rio de Janeiro, v. 41, n. 3, p.569-592, set.-dez.

TEIXEIRA, H. J. \& SANTANA, S. M. (coords.). 1994. Remodelando a gestão pública. São Paulo : E. Blucher.

VOGEL, D. 1986. National Styles of Regulation : Environmental Policy in Great Britain and the United States. Ithaca : Cornell University Press.

VOGEL, S. K. 1996. Free Markets, More Rules : Regulatory Reform in Advanced Industrial Economies. Ithaca : Cornell University Press.

WERLANG, S. R. C. 1996. Brasil na virada do século : um país liberal. Dados, Rio de Janeiro, v. 39 , n. 3, p.367-375, set.-dez. 


\section{OUTRAS FONTES}

ANATEL. 1996. Lei in. 5 070, de 07.jul.1996. Cria o Fundo de Fiscalização das Telecomunicações e dá outras providências. http://www.anatel.gov.br/Tools/frame.asp?link=/biblioteca/leis/ lei_5070_07_07_1966.pdf : 01.maio.2002.

.2000. Lei n. 9998 , de 17.ago.2000. Institui o Fundo de Universalização dos Serviços de Telecomunicações. http://www.anatel.gov.br/ Tools/frame.asp?link=/biblioteca/leis/ lei_9998_17_08_2000.pdf:01.maio.2002.

ANEEL. 2002. Agência Nacional de Energia Elétrica. http://www.aneel.gov.br : 01.fev.2002.

A reabilitação do Estado. Jornal do Brasil, Rio de Janeiro, 18.set.1999.

Ataque ao reajuste. Jornal do Brasil, Rio de Janeiro, 14.out.1999.

CALADO, L. 1998. Privatização estimula investimentos. Gazeta Mercantil, São Paulo, 15.dez. Caderno "Tecnologia da informação", p. 4.

CARNEIRO, D. D. 1999. Crescer é resultado. Jornal do Brasil, Rio de Janeiro, 02.set.

CEPEL. 1997. Relatório de atividades do Cepel - 1996. Brasília : Centro de Pesquisas Elétricas/ Eletrobrás/Ministério de Minas e Energia. Digit.

Correio da Unesco. 1999. Rio de Janeiro.

CPQD. s/d. CPqD no novo contexto das telecomunicações brasileiras. Campinas : Centro de Pesquisa e Desenvolvimento. Digit.

FRANCO, G. H. B. 1999. Privatização : as novas fronteiras? Jornal do Brasil, Rio de Janeiro, 15.set.

GRACIOSA, H. M. M. 1998. Diretor de Pesquisa e Desenvolvimento da TELEBRÁS. Fundo para o Desenvolvimento Tecnológico das Telecomunicações - FDTT - Projeto de Lei $n$. 3939/97 - Reunião de Audiência Pública da Comissão de Ciência e Tecnologia da Câmara dos Deputados. 03.jun.1998. Mimeo.

Gazeta Mercantil, São Paulo. Diversos números a partir de 1997.
Jornal do Brasil, Rio de Janeiro. Diversos números a partir de 1997.

MINISTÉRIO DA CIÊNCIA E TECNOLOGIA. 2000. Lei 9 991, de 24.jul.2000. Dispõe sobre realização de investimentos em pesquisa e desenvolvimento e em eficiência energética por parte das empresas concessionárias, permissionárias e autorizadas do setor de energia elétrica, e dá outras providências. http://www.mct. gov.br/legis/leis/9991_2000.htm 01.maio.2002.

. 2001a. Informações. http://www.mct. gov.br/Temas/Fundos/ctinfo_pg.htm : 01.maio. 2001.

. 2001b. Perguntas e respostas. http:// www.mct.gov.br/Temas/Fundos/ perg_resp.htm\#O que são fundos : 01.fev.2001.

2002. Lei de informática. http:// www.mct.gov.br/sepin/imprensa/ noticias_anteriores/lei_informatica_ant.htm : 01.maio.2002.

MINISTÉRIO DAS COMUNICAÇÕES. GABINETE DO MINISTRO. 1996. Exposição de motivos n. 231. Brasília : Ministério das Comunicações.

MINISTÉRIO DAS COMUNICAÇÕES. 2000a. FUNTTEL. http://www.mc.gov.br/funttel : 01.maio. 2002 .

2000b. Lei n. 10 052, de 28.nov.2000. Institui o Fundo para o Desenvolvimento Tecnológico das Telecomunicações - Funttel, e dá outras providências. http://www.mc. gov.br/funttel/1_10052_28112000.htm : 01 . maio. 2002 .

O Estado de São Paulo. Diversos números a partir de 1997.

Política do espaço. Folha de São Paulo. Editorial. 15.set.1999.

PRADO, M. C. R. M. 1999. Um exemplo a ser seguido. Gazeta Mercantil, São Paulo, 2123.maio. 